\title{
Synthesis of cuprous oxide nanocubes combined with chitosan nanoparticles and its application to $p$-nitrophenol degradation
}

\author{
Tran Thi Bich Quyen ${ }^{1 *}$, Ngo Nguyen Tra My¹, Do Thi Thuy Ngan¹, Duy Toan Pham², \\ Doan Van Hong Thien ${ }^{1}$
}

\author{
${ }^{1}$ Department of Chemical Engineering, College of Technology, Can Tho University, \\ 3/2 Street, Ninh Kieu District, Can Tho City, Vietnam \\ ${ }^{2}$ Department of Chemistry, College of Natural Sciences, Can Tho University, \\ 3/2 Street, Ninh Kieu District, Can Tho 900000, Vietnam
}

*Corresponding author: ttbquyen@ctu.edu.vn; ORCID ID: 0000-0002-9304-5544

Received: 8 June 2021; revised: 1 September 2021; accepted: 2 September 2021

\begin{abstract}
For the first time, cuprous oxide nanocubes ( $\mathrm{Cu}_{2} \mathrm{O} \mathrm{NCBs}$ ) were successfully combined with chitosan nanoparticles (CS NPs) to generate $\mathrm{Cu}_{2} \mathrm{O}$ NCBs/CS NPs composites material with highly optical property and photocatalytic activity using a simple and eco-friendly synthetic approach at room temperature for $30 \mathrm{~min}$. The synthesized $\mathrm{Cu}_{2} \mathrm{O} \mathrm{NCBs/CS} \mathrm{NPs}$ were characterized by Ultraviolet-visible spectroscopy (UV-vis), Fourier transform infrared spectroscopy (FTIR), X-ray Diffraction (XRD), Transmission Electron Microscope (TEM) and Energy-dispersive X-ray spectroscopy (EDX). Results show that the $\mathrm{Cu}_{2} \mathrm{O}$ NCBs/CS NPs composites possessed an average particle size of $\sim 3-5 \mathrm{~nm}$; in which, $\mathrm{Cu}_{2} \mathrm{O}$ had the form of nanocubes with a size of $\sim 3-4 \mathrm{~nm}$ and CS NPs had spherical shape with a size of $\sim 4-5 \mathrm{~nm}$. In addition, the composition percentages of elements presented in $\mathrm{Cu}_{2} \mathrm{O}$ NCBs/CS NPs composites material were: $\mathrm{Cu}(23.99 \%)$, $\mathrm{O}(38.18 \%)$, and $\mathrm{C}(33.61 \%)$. Moreover, $\mathrm{Cu}_{2} \mathrm{O}$ NCBs/CS NPs composites material was also investigated for photocatalytic activity applied in $p$-nitrophenol degradation. The obtained results showed that the catalytic capability of $\mathrm{Cu}_{2} \mathrm{O} \mathrm{NCBs/CS}$ NPs for $p$-nitrophenol reduction reached the highest efficiency of $>55 \%$ in the treatment time of 25 min, and this efficiency was higher than that of the $\mathrm{ZnO@chitosan} \mathrm{nanoparticles} \mathrm{catalyst} \mathrm{under} \mathrm{the} \mathrm{same} \mathrm{conditions.}$
\end{abstract}

Keywords: Cuprous oxide nanocubes ( $\mathrm{Cu}_{2} \mathrm{O}$ NCBs), chitosan nanoparticles (CS NPs), cuprous oxide nanocubes/chitosan nanoparticles ( $\mathrm{Cu}_{2} \mathrm{O} \mathrm{NCBs} / \mathrm{CS} \mathrm{NPs}$ ) composites, photocatalytic activity, $p$-nitrophenol.

\section{INTRODUCTION}

As a side effect of the industrialization, many polluting compounds were discharged into the environment, especially the water environment. To this end, $p$-Nitrophenol $(p-N P)$ is one of the most refractory and stable nitroaromatic compounds due to its resistance to chemical and biological degradation [1]. This organic toxic is widely used in the synthesis of plenty industrial and agricultural products such as pesticides, herbicides, petrochemicals, explosives, pharmaceuticals, and dyes [2 - 4]. p-NP contamination has significant effects on human and animal health. Thus, $p$-NP was listed as one of the priority hazardous and toxic pollutant by the U.S. Environmental Protection Agency (EPA) [5]. Various studies have been performed to reduce the content of $p$-NP in solution, such as photocatalytic hydrogenation $[1,6]$, photoelectrocatalytic $[7,8]$, biological degradation
[9], and metal-free catalyst [10]. In recent years, the reduction of $p$-NP to $p$-aminophenol ( $p$-AP) have gained attention from the scientific community, since $p$-AP is a low toxic compound that is useful as an important intermediate in the preparation of pharmaceuticals, lubricants, and dyes [11].

Obviously, metal oxide-based semiconductor nanomaterials have received much attention due to their excellent physical and chemical properties, which can be applied in various practical fields. In particular, cuprous oxide $\left(\mathrm{Cu}_{2} \mathrm{O}\right)$ is considered as an important $p$-type semiconductor materials because of its attractive optical properties. The bandgap energy of $\mathrm{Cu}_{2} \mathrm{O}$ is between $1.95-2.2 \mathrm{eV}$ [12]. Therefore, it represents a promising candidate for many applications such as photovoltaic, sensors, superconductors, and especially, photocatalysis [13].

(C) The Author(s). 2021 Open access. This article is distributed under the terms of the Creative Commons Attribution 4.0 International License (http://creativecommons.org/licenses/by/4.0/), which permits unrestricted use, distribution, and reproduction in any medium, provided you give appropriate credit to the original author(s) and the source, provide a link to the Creative Commons license, and indicate if changes were made. 
The photocatalytic ability of $\mathrm{Cu}_{2} \mathrm{O}$ has been extensively researched the removal of pollutants from aqueous medium such as methyl orange [9], methyl blue [10], brilliant red X-3B [11], and $p$-NP $[12,13]$. Up to now, various studies have been devoted to the synthesis of $\mathrm{Cu}_{2} \mathrm{O}$ nanoparticles (NPs) that adopt various morphologies such as: nanocubes [14], octahedra [14, 15], spherical particles [16], and nanowires [17]. The catalytic ability of $\mathrm{Cu}_{2} \mathrm{O}$ is influenced by its morphology since the structure-related band gap energy is essential to their photocatalytic performance [7]. The photocatalytic activity of pure $\mathrm{Cu}_{2} \mathrm{O}$ is very low because of the easy recombination between photo-generated electrons and holes, be oxidized or easy to aggregate to micron-size [11]. Several methods including the incorporation of $\mathrm{Cu}_{2} \mathrm{O}$ composites with noble metal [18] and other semiconductors [19] have been developed to enhance the photocatalytic activity of pure $\mathrm{Cu}_{2} \mathrm{O}$ under visible-light radiation. In this work, a substrate that is able to disperse and stabilize the $\mathrm{Cu}_{2} \mathrm{O}$ NPs and enhance its photocatalytic performance has been proposed. Chitosan (CS) is one of the most commonly used natural biopolymers [20]. CS is an abundant low-cost raw material with high reproducibility and biodegradability [21]. CS NPs possess surface and interface effect, small size and quantum size effect [22]. In addition, CS NPs can be easily combined with metal ions or metal oxides to form composites (due to the existence of $-\mathrm{NH}_{2}$ and $-\mathrm{OH}$ functional groups in the molecule). These composites have a stable structure and shape, and higher photocatalytic activity than the original metal oxide properties [23].

To the best of our knowledge, there have been no published reports concerning the synthesis of a composite material comprised of both $\mathrm{Cu}_{2} \mathrm{O}$ nanocubes and chitosan nanoparticles (denoted here as $\mathrm{Cu}_{2} \mathrm{O}$ NCBs/CS NPs). Herein, $\mathrm{Cu}_{2} \mathrm{O}$ NCBs were successfully synthesized and combined with CS NPs to generate $\mathrm{Cu}_{2} \mathrm{O}$ NCBs/CS NPs composites by a rapid and simple method. Besides, the properties characterizations of this nanocomposites material have also been analyzed. Moreover, the synthesized $\mathrm{Cu}_{2} \mathrm{O} \mathrm{NCBs} / \mathrm{CS}$ NPs nanocomposites have been used as a catalyst material for the degradation of $p$-nitrophenol.

\section{EXPERIMENTAL}

Materials: Copper sulfate $\left(\mathrm{CuSO}_{4} \times 5 \mathrm{H}_{2} \mathrm{O} ; 99.5 \%\right)$, Sodium borohydride $\left(\mathrm{NaBH}_{4} ; 99 \%\right)$, Sodium hydroxide $(\mathrm{NaOH} ; 99 \%)$, and Hydrazine hydrate $\left(\mathrm{N}_{2} \mathrm{H}_{4} \times 2 \mathrm{H}_{2} \mathrm{O} ; 99 \%\right)$ were purchased from Sigma-Aldrich (Merck). Acetic acid $\left(\mathrm{CH}_{3} \mathrm{COOH} ; 99 \%\right)$ and D-glucose $\left(\mathrm{C}_{6} \mathrm{H}_{12} \mathrm{O}_{6} \times \mathrm{H}_{2} \mathrm{O}, 99.5 \%\right)$ were bought from Hemidia, India. Chitosan of Vietnam; and $p$-Nitrophenol $\left(\mathrm{C}_{6} \mathrm{H}_{5} \mathrm{NO}_{3}, 99 \%\right)$ was purchased from Dengfeng Chemical Technology Co., Ltd,. All solutions were prepared with deionized water $\left(\mathrm{DI} \mathrm{H}_{2} \mathrm{O}\right)$ from a MilliQ system.

Preparation of cuprous oxide nanocubes $\left(\mathrm{Cu}_{2} \mathrm{O}\right.$ NCBs): Typically, $70.30 \mathrm{mg}$ of $\mathrm{CuSO}_{4} \times 5 \mathrm{H}_{2} \mathrm{O}$ and
$0.361 \mathrm{~g}$ of D-glucose were dissolved in $100 \mathrm{~mL}$ of deionized water under vigorous stirring. After $15 \mathrm{~min}$, $100 \mu \mathrm{L}$ of $\mathrm{NaOH}(10 \mathrm{M}$ ) was added dropwise into the copper sulfate solution and stirred for $15 \mathrm{~min}$. Then, $200 \mu \mathrm{L}$ of $\mathrm{N}_{2} \mathrm{H}_{4} \times 2 \mathrm{H}_{2} \mathrm{O}(2 \mathrm{M})$ was added into the mixture and continuous stirred for $20-30 \mathrm{~min}$. As a result, the solution color changed from blue to orangered. Finally, the prepared-solution was centrifuged and washed several times with $\mathrm{DI} \mathrm{H}_{2} \mathrm{O}$ to neutral $\mathrm{pH}$ and re-dispersed in $15 \mathrm{~mL}$ of $\mathrm{DI} \mathrm{H}_{2} \mathrm{O}$ to use for next steps.

\section{Preparation of chitosan nanoparticles (CS NPs):} $1 \mathrm{~g}$ of chitosan (CS) was added into $100 \mathrm{~mL}$ of acetic acid $\left(0.5 \%\right.$ in $\left.\mathrm{DI} \mathrm{H}_{2} \mathrm{O}\right)$ and stirred at $60{ }^{\circ} \mathrm{C}$ for $1 \mathrm{~h}$. Then, $10 \mathrm{~mL}$ of sodium triphosphate (STPP) $(1 \mathrm{mg} / \mathrm{mL}$ in $\mathrm{DI}_{2} \mathrm{O}$ ) was mixed with as-prepared CS solution and stirred for $30 \mathrm{~min}$. Finally, the prepared CS NPs solution was centrifuged and washed three times with $\mathrm{DI} \mathrm{H}_{2} \mathrm{O}$ to obtain CS NPs with high purity and dispersed in $100 \mathrm{~mL}$ of $\mathrm{DI} \mathrm{H}_{2} \mathrm{O}$ to use for next experiments.

Synthesis of $\mathrm{Cu}_{2} \mathrm{O}$ NCBs/CS NPs composites: To formulate $\mathrm{Cu}_{2} \mathrm{O}$ NCBs/CS NPs composites material, the prepared CS NPs was added to $\mathrm{Cu}_{2} \mathrm{O}$ NCBs solution. Various volumes of CS NPs solution of respective: $100 \mu \mathrm{L}, 200 \mu \mathrm{L}, 500 \mu \mathrm{L}$, and $1000 \mu \mathrm{L}$ was added dropwise into $5 \mathrm{~mL}$ of $\mathrm{Cu}_{2} \mathrm{O}$ NCBs solution and stirred at room temperature for 30 min to obtain $\mathrm{Cu}_{2} \mathrm{O}$ NCBs/CS NPs composites material. This $\mathrm{Cu}_{2} \mathrm{O}$ NCBs/ CS NPs composite will be used as a photocatalyst material for $p$-nitrophenol degradation.

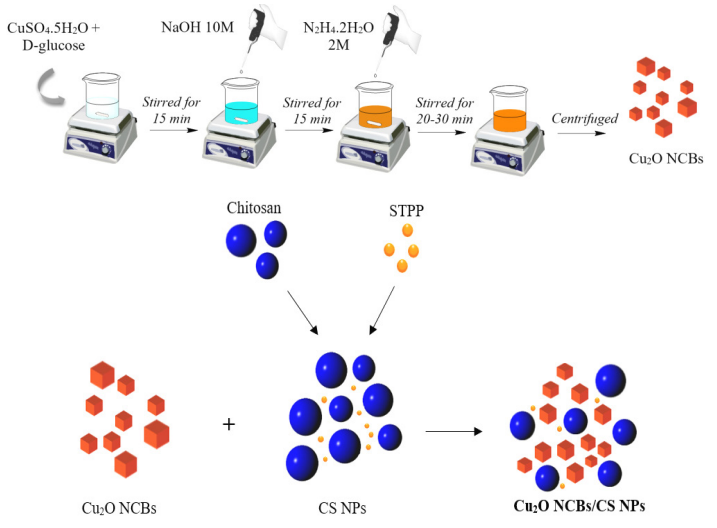

Scheme.1. Synthesis of $\mathrm{Cu}_{2} \mathrm{O}$ NCBs/CS NPs nanocomposites

Catalytic activity test of $\mathrm{Cu}_{2} \mathrm{O}$ NCBs/CS NPs composites: $30 \mu \mathrm{L}$ of $\mathrm{NaBH}_{4}(3 \mathrm{M})$ and $750 \mu \mathrm{L}$ of $p$-nitrophenol ( $p$-NP) (25 ppm) were stirred in the dark for 10 min to obtain the adsorption-desorption equilibrium. Then, under UV light (395 nm, OEM, Philips), $1.5 \mathrm{~mL}$ of $\mathrm{Cu}_{2} \mathrm{O} \mathrm{NCBs} / \mathrm{CS}$ NPs (0.22 mg of $\mathrm{Cu}_{2} \mathrm{O}$ NCBs loading) was added to the prepared-solution under constant stirring. The reaction was determined as soon as the catalyst was added into the solution. Consequently, the material treatment was separated by centrifugation within $2 \mathrm{~min}$. On the other hand, an experiment to investigate the reduction of $p$-NP by $\mathrm{NaBH}_{4}$ in the 
absence of catalyst material was also performed for comparison. The amount of lost $p$-NP was determined according to Equation 1.

$$
H \%=100 .\left(\Delta C / C_{0}\right)
$$

Where $\Delta C=C_{0}-C$ with $C_{0}$ and $C$ are the initial and final concentrations of $p$-nitrophenol, respectively.

Instrumentation: The $\mathrm{Cu}_{2} \mathrm{O}$ NCBs/CS NPs synthesis process was observed by recording the absorbance spectra between 200 and $900 \mathrm{~nm}$ on the UV-vis spectrophotometer (Thermo Scientific Evolution 60S UV-Vis spectrophotometer, USA). X-ray diffraction (XRD) was performed on a D8-Advance machine (Bruker, Germany) in the $2 \theta$ range of $10^{\circ}-80^{\circ}$.

The Fourier transform infrared (FT-IR) spectra were obtained by Perkin Elmer Frontier MIR/NIR (Perkin Elmer, USA) in the range of $4000-400$ $\mathrm{cm}^{-1}$. Transmission electron microscopy (TEM) characterization was performed on a Jem1010 device (Joel Company, Japan). Chemical properties and constituent components were analyzed via Energydispersive X-ray spectroscopy (EDX H-7593, Horiba, England).

\section{RESULTS AND DISCUSSION}

Characterization and morphology of $\mathrm{Cu}_{2} \mathrm{O} \mathrm{NCBs} /$ CS NPs composites: Fig. 1 shows the UV-vis result of the synthesized $\mathrm{Cu}_{2} \mathrm{O}$ NCBs/CS NPs composites with various volumes of CS NPs solution. Obviously, the amount of CS NPs influenced the synthesis of $\mathrm{Cu}_{2} \mathrm{O}$ NCBs/CS NPs composites. Fig. $1 \mathrm{~A}(\mathrm{a})$, (b) indicate that the initial characteristic peak at $470 \mathrm{~nm}$ of $\mathrm{Cu}_{2} \mathrm{O}$ NCBs shifted to the peak at $500 \mathrm{~nm}$ and $480 \mathrm{~nm}$ with higher absorption intensity corresponding to the added volume of CS NPs solution of $100 \mu \mathrm{L}$ and $200 \mu \mathrm{L}$, respectively. Moreover, the absorption band in the range from 550 $\mathrm{nm}$ to $900 \mathrm{~nm}$ of $\mathrm{Cu}_{2} \mathrm{O}$ NCBs tends to increase strongly (Fig. 1A). Besides, a band gap with energy level at 2.08 $\mathrm{eV}$ of the synthesized $\mathrm{Cu}_{2} \mathrm{O}$ NCBs was converted to $2.04 \mathrm{eV}$ when combined with $200 \mu \mathrm{L}$ of CS NPs solution - as shown in Fig. 1B. Therefore, it can be confirmed that CS NPs have the ability to enhance the optical properties of $\mathrm{Cu}_{2} \mathrm{O}$ NCBs.

When the volume of CS NPs solution is excessive, the UV spectra showed the gradual decrease and disappearance of the characteristic peak and optical absorption band of composites material (Fig. 1A (d),(e)). Due to the interaction between the excess acid in the CS NPs solution with $\mathrm{Cu}_{2} \mathrm{O}$ NCBs to form $\mathrm{Cu}^{2+}$ ion or nano $\mathrm{Cu}$, leading to a significant loss of $\mathrm{Cu}_{2} \mathrm{O}$ NCBs, thereby making the optical absorbance of the material decreased.

Thus, the volume of CS NPs solution at $200 \mu \mathrm{L}$ was chosen as the optimal condition for the combination of CS NPs with $\mathrm{Cu}_{2} \mathrm{O}$ NCBs to generate $\mathrm{Cu}_{2} \mathrm{O}$ NCBs/CS NPs composites.
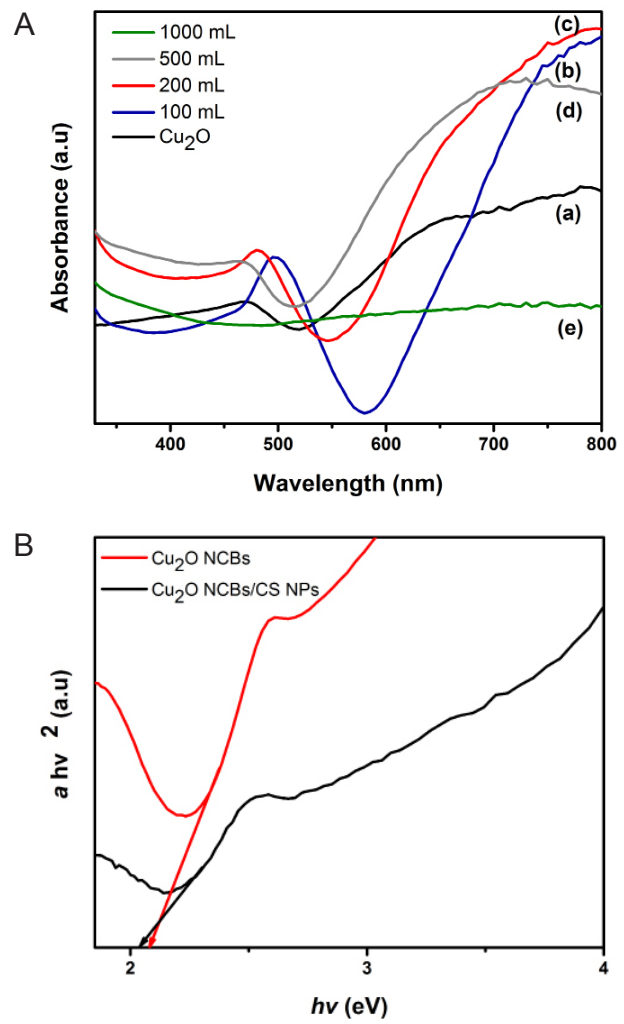

Fig. 1A. UV-Vis spectra of (a) $\mathrm{Cu}_{2} \mathrm{O}$ nanocubes $\left(\mathrm{Cu}_{2} \mathrm{O}\right.$ $\mathrm{NCBs}$ ) and $\mathrm{Cu}_{2} \mathrm{O}$ NCBs/CS NPs composites with different volumes of CS NPs: (b) 100, 200, 500, and $1000 \mu \mathrm{L}$.

B. Graphical determination of direct optical band gap of (a) $\mathrm{Cu}_{2} \mathrm{O}$ NCBs/CS NPs and (b) $\mathrm{Cu}_{2} \mathrm{O}$ NCBs, respectively.

To study the structure of $\mathrm{Cu}_{2} \mathrm{O}$ NCBs/CS NPs composites, the FTIR spectra of pure CS NPs and composites were applied (Fig. 2). The FTIR spectra of the obtained CS NPs showed characteristic oscillations at $3414 \mathrm{~cm}^{-1}$ and $2926 \mathrm{~cm}^{-1}$, attributed to the stretching vibration of $-\mathrm{NH}_{2},-\mathrm{OH}$, and aliphatic $-\mathrm{CH}_{2}$ and $-\mathrm{CH}_{3}$ groups, respectively [24]. The vibration bands at 1641 $\mathrm{cm}^{-1}$ and $1087 \mathrm{~cm}^{-1}$ are corresponding to the bending vibrations of $-\mathrm{NH}$ and $-\mathrm{OH}$ groups.

The transformation of chemical groups in CS NPs when forming of $\mathrm{Cu}_{2} \mathrm{O} \mathrm{NCBs/CS} \mathrm{NPs} \mathrm{composites} \mathrm{was} \mathrm{shown}$ in Fig. 2(a). The broad absorption band between 3150$3414 \mathrm{~cm}^{-1}$ became a sharp peak at $3428 \mathrm{~cm}^{-1}$ due to the compression of the $-\mathrm{OH}$ group, possibly caused by the water molecule adsorbed on the surface of $\mathrm{Cu}_{2} \mathrm{O}$ NCBs. Additionally, the peaks at $1641 \mathrm{~cm}^{-1}$ and $1087 \mathrm{~cm}^{-1}$ were shifted to $1611 \mathrm{~cm}^{-1}$ and $1060 \mathrm{~cm}^{-1}$, respectively, indicating that the amine functional group $(-\mathrm{NH})$ and the hydroxyl group $(-\mathrm{OH})$ participated in the complexation process [25]. At the same time, the narrow oscillation range from $1450-1300 \mathrm{~cm}^{-1}$, which was attributed to the fluctuation of C-N bonding in CS NPs and appeared with a sharp peak at $1411 \mathrm{~cm}^{-1}$ in FTIR spectra of $\mathrm{Cu}_{2} \mathrm{O}$ NCBs/CS NPs. Besides, the characteristic absorption bands of $\mathrm{Cu}_{2} \mathrm{O}$ NCBs were shown at $720 \mathrm{~cm}^{-1}$ and 618 $\mathrm{cm}^{-1}$ [7]. The bands shift in the region from 1700-700 
$\mathrm{cm}^{-1}$ is influenced by the absorption peak of $\mathrm{Cu}-\mathrm{O}$ bonds in this region [15]. As a result, the maximum absorption peak intensity of $\mathrm{Cu}_{2} \mathrm{O} \mathrm{NCBs} / \mathrm{CS} \mathrm{NPs}$ composites are significantly changed compared to the pure CS NPs. This result was due to the strong surface interaction between $\mathrm{CS} \mathrm{NPs}$ and $\mathrm{Cu}_{2} \mathrm{O}$ NCBs.

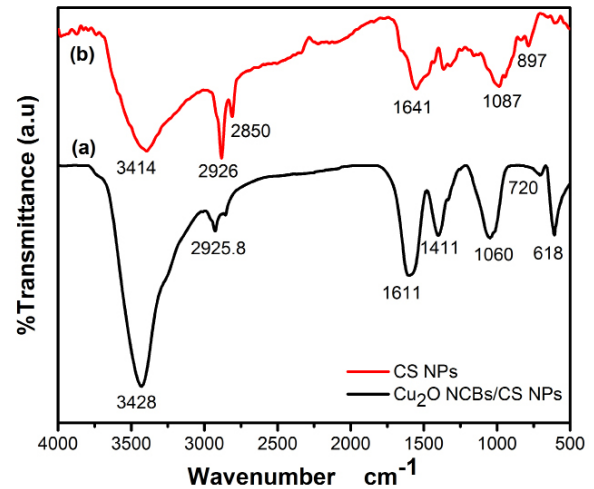

Fig. 2. FTIR spectra of (a) $\mathrm{Cu}_{2} \mathrm{O} \mathrm{NCBs} / \mathrm{CS}$ NPs composites and (b) $\mathrm{CS}^{2} \mathrm{NPS}$, respectively.

The X-ray diffraction (XRD) results of $\mathrm{CS} \mathrm{NPs}$ and $\mathrm{Cu}_{2} \mathrm{O}$ NCBs/CS NPs composites are clearly shown in Fig. 3. Fig. 3(a) shows that there are a large amounts of hydroxyl and amino groups in the structure of CS NPs. The presence of STPP induces cross-links in CS circuits to form CS NPs with amorphous structure. This result is in complete agreement with a previous work [26]. The synthesized CS NPs structure improves metal ions absorption ability of CS NPs [27].

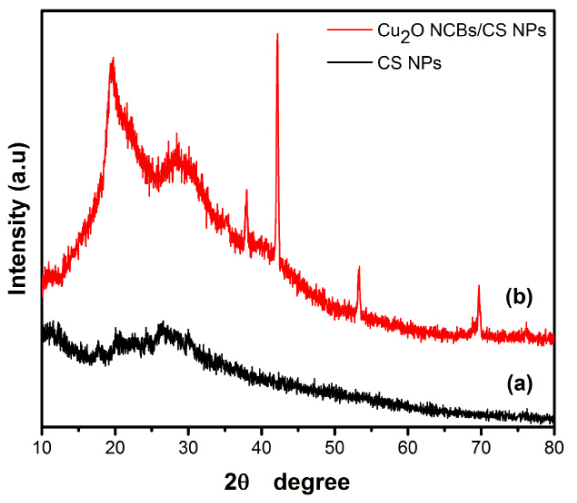

Fig. 3. X-ray diffraction (XRD) patterns of (a) CS NPS and (b) $\mathrm{Cu}_{2} \mathrm{O} \mathrm{NCBs/CSNPs} \mathrm{composites,} \mathrm{respectively.}$

When CS NPs was added to the $\mathrm{Cu}_{2} \mathrm{O}$ NCBs (Fig. $3(b))$, the characteristic diffraction peaks of $\mathrm{Cu}_{2} \mathrm{O}$ were identified at six clear peaks with $2 \theta$ values of $29.5^{\circ}$; $38^{\circ} ; 42.1^{\circ} ; 53.2^{\circ} ; 70^{\circ}$; and $76.18^{\circ}$, corresponding to the crystal planes (110); (111); (200); (211); (311); and (222). These diffraction peaks completely coincide with the $\mathrm{Cu}_{2} \mathrm{O}$ NCBs structure (JCPDS Card No. 05-0667) [28]. In addition, no other diffraction peaks arising from possible impurities such as $\mathrm{Cu}, \mathrm{CuO}$ or $\mathrm{Cu}(\mathrm{OH})_{2}$ were detected, thus, confirming the formation of pure $\mathrm{Cu}_{2} \mathrm{O}$ NPs [24]. The increase in the intensity of the diffraction peak between $\mathrm{Cu}_{2} \mathrm{O}$ NCBs/CS NPs composites and CS NPs was caused by diffraction/interlacing between the amorphous structure of CS NPs and the crystal structure of $\mathrm{Cu}_{2} \mathrm{O}$ NCBs. This change of CS NPs represents a successful interaction/binding between CS NPs and $\mathrm{Cu}_{2} \mathrm{O}$ NCBs to form $\mathrm{Cu}_{2} \mathrm{O}$ NCBs/CS NPs composites.

A

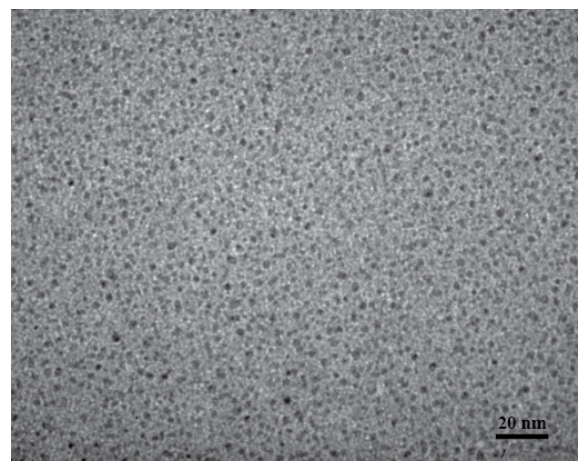

B

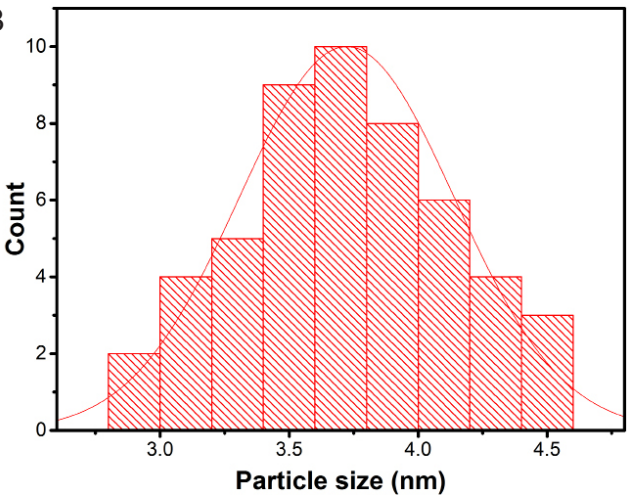

Fig. 4A. TEM image of $\mathrm{Cu}_{2} \mathrm{O}$ NCBs/CS NPs composites;

B. Particle size distribution of $\mathrm{Cu}_{2} \mathrm{O}$ NCBs/CS NPs composites, respectively.

The morphology and size of the product was studied by TEM, Fig. 4A. The result shows that $\mathrm{Cu}_{2} \mathrm{O}$ NCBs have the cubic structure with an average particle size $\sim 3-4$ $\mathrm{nm}$; and CS NPs have spherical shape with an average particle size $\sim 4-5 \mathrm{~nm}$. Thus, the synthesized $\mathrm{Cu}_{2} \mathrm{O}$ $\mathrm{NCBs} / \mathrm{CS}$ NPs composites have an average particle size of $\sim 3-5 \mathrm{~nm}$ (Fig. 4B). Additionally, the $\mathrm{Cu}_{2} \mathrm{O}$ NCBs/CS NPs composites particles were uniformly distributed and dispersed without agglomeration.

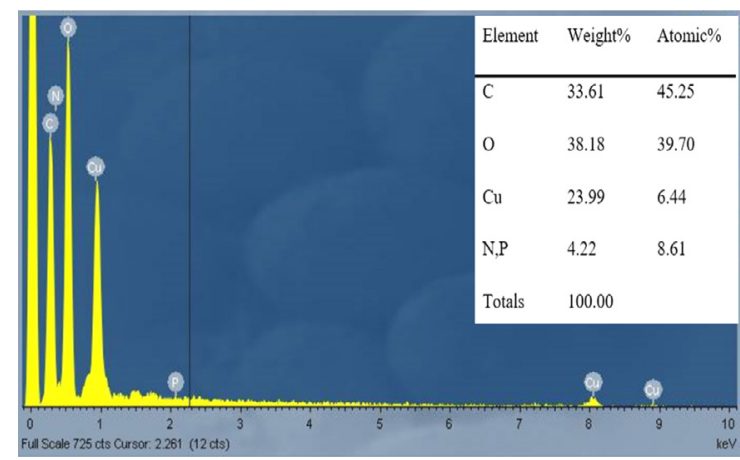

Fig. 5. Energy dispersive X-ray (EDX) spectra of $\mathrm{Cu}_{2} \mathrm{O}$ NCBs/CS NPs composites. 
EDX analysis was used to determine the composition of the synthesized $\mathrm{Cu}_{2} \mathrm{O} \mathrm{NCBs} / \mathrm{CS}$ NPs composites sample. Fig. 5 shows that the $\mathrm{Cu}_{2} \mathrm{O}$ NCBs/CS NPs composites comprised elemental compositions including: Cu (23.99\%), O (38.18\%), C (33.61\%), and other elements like $\mathrm{N}$ and $\mathrm{P}$. These results indicated that the presence of $\mathrm{Cu}_{2} \mathrm{O}$ NCBs and CS NPs in the synthesized $\mathrm{Cu}_{2} \mathrm{O}$ NCBs/CS NPs nanocomposites sample.

Photocatalytic activity of $\mathrm{Cu}_{2} \mathrm{O}$ NCBs/CS NPs composites for p-nitrophenol degradation: The reduction of $p-\mathrm{NP}$ by $\mathrm{NaBH}_{4}$ without using photocatalytic is presented in Fig. 6. Firstly, the UVvis spectrum (Fig. 6(a)) indicated that the absorption wavelength of the initial $p$-NP was shifted from 317 to $400 \mathrm{~nm}$ immediately upon the addition of $\mathrm{NaBH}_{4}$, corresponding to a significant change in solution color from light yellow to yellow-green due to the formation of 4-nitrophenolate ion. The reduction of $\mathrm{p}-\mathrm{NP}$ by $\mathrm{NaBH}_{4}$ is thermodynamically feasible but possesses a high kinetic impediment between negative ions that repel each other between $p$-nitrophenolate and $\mathrm{BH}_{4}^{-}$in the absence of an effective catalyst [29, 30].

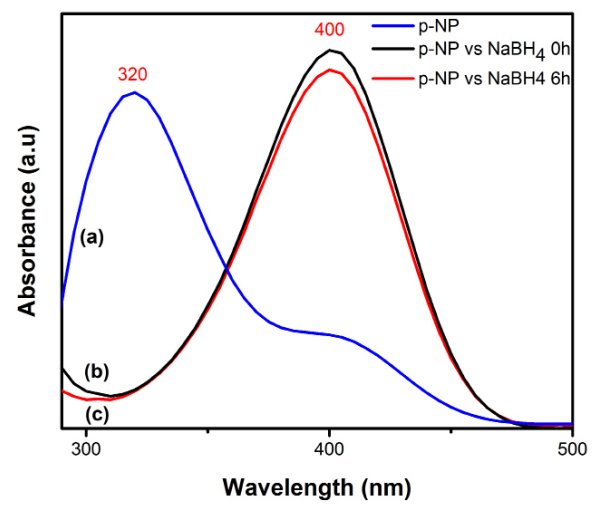

Fig. 6. UV-vis spectra of p-nitrophenol (p-NP) reduction without photocatalysts.

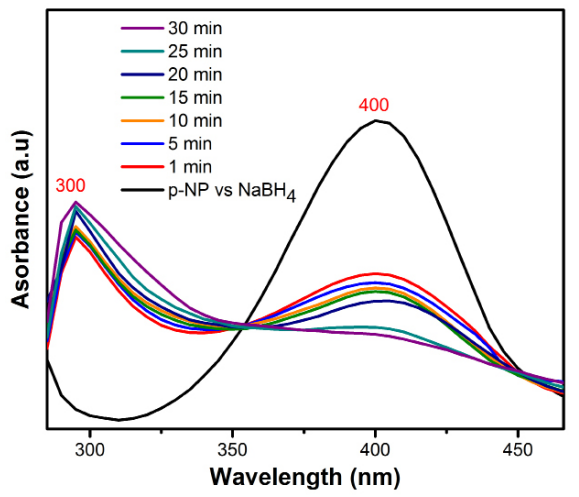

Fig. 7. UV-vis spectra of $p$-nitrophenol reduction with various reaction times using $\mathrm{Cu}_{2} \mathrm{O}$ NCBs/CS NPs composites as a photocatalyst material.

As showed in Fig. 6(c), the yellow-green decolorization of the $p$-NP solution after $6 \mathrm{~h}$ has no significant change compared to that at the initial time. The decomposition percentage of $p$-NP after $6 \mathrm{~h}$ in the absence of catalyst was only $3.68 \%$. This represented an extremely slow reaction rate in the absence of a catalyst. Using different catalysts in this reaction could yield disparate results due to the fact that many oxides are also unable to degrade $p$-NP under different reaction conditions [29]. In the presence of $\mathrm{Cu}_{2} \mathrm{O}$ NCBs/CS NPs composites catalyst, the results of $p$-NP degradation (Fig. 7) are significantly different from those of $\mathrm{NaBH}_{4}$ without catalytic materials. The absorption peak at $400 \mathrm{~nm}$ of $p$-nitrophenolate ions was gradually decreased in intensity. At the same time, there was the formation and intensification of another absorption peak at 300 $\mathrm{nm}$, which is the characteristic absorption peak of $p$-aminophenol $(p-\mathrm{AP})$. Therefore, it is demonstrated that there was a conversion from $p$-NP to $p$-AP in the presence of $\mathrm{Cu}_{2} \mathrm{O} \mathrm{NCBs} / \mathrm{CS}$ NPs.

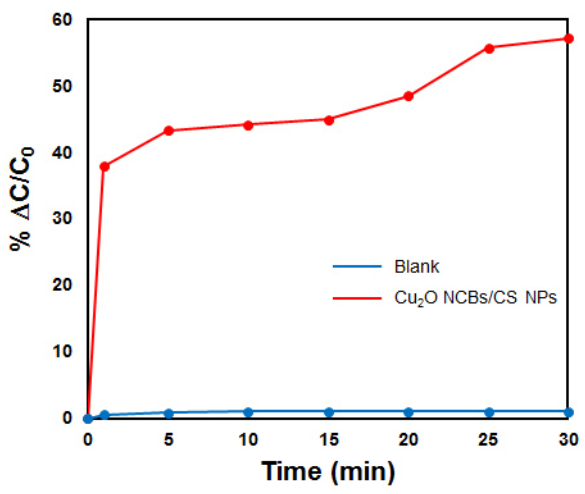

Fig. 8. Decomposition percent versus reaction time for the reduction of $p$-NP over (a) blank sample without catalyst and (b) using $\mathrm{Cu}_{2} \mathrm{O}$ NCBs/CS NPs composites catalyst, respectively.

Meanwhile, the color of solution also showed that $p$-NP was reduced in the reaction, the characteristic yellow color of $p$-nitrophenolate ion was lost and changed to a clear solution of $p$-AP. Indeed, the results of the graph in Fig. 8 show that in the presence of $\mathrm{Cu}_{2} \mathrm{O} \mathrm{NCBs} / \mathrm{CS}$ NPs photocatalysts, the higher the reaction time, the greater the percentage loss of $p$-nitrophenolate ions. The percentage (\%) of $p$-NP decomposition in $1 \mathrm{~min}$ was $37.92 \%$. After $25 \mathrm{~min}$, this value was $\sim 55.72 \%$ (Fig. 8). Thus, it is confirmed that the positive charges on the $\mathrm{Cu}_{2} \mathrm{O}$ NCBs/CS NPs composites' surfaces facilitated the interaction between nitrophenolate and $\mathrm{BH}_{4}{ }^{-}$ions. At the same time, the inactivity of $\mathrm{ZnO@CS}$ NPs in this reaction can be attributed to the absence of electron relay process. In addtion, the bandgap energy of $\mathrm{Cu}_{2} \mathrm{O}$ NCBs/CS NPs (2.04 eV) is lower than that of $\mathrm{ZnO@}$ CS NPs (3.06 eV) and the existence of copper (Cu) metal on the surface of $\mathrm{Cu}_{2} \mathrm{O}$ NCBs made the electron transfer occur faster. This result was completely consistent with previous studies [29]. 


\section{CONCLUSIONS}

$\mathrm{Cu}_{2} \mathrm{O}$ NCBs/CS NPs composites have been successfully synthesized by simple physical mixing between $\mathrm{Cu}_{2} \mathrm{O}$ NCBs and CS NPs at room temperature for $30 \mathrm{~min}$. $\mathrm{Cu}_{2} \mathrm{O} \mathrm{NCBs} / \mathrm{CS} \mathrm{NPs}$ composites have an average particle size $~ 3-5 \mathrm{~nm}$; in which, $\mathrm{Cu}_{2} \mathrm{O}$ NCBs have the form of cubic particles $\left(\mathrm{Cu}_{2} \mathrm{O}\right.$ nanocubes $\mathrm{Cu}_{2} \mathrm{O}$ NCBs) with a dimension of $\sim 3-4 \mathrm{~nm}$ and $\mathrm{CS}$ NPs have spherical shape with a particle size of $\sim 4-5$ $\mathrm{nm}$. Besides, the percent (\%) composition of elements presented in $\mathrm{Cu}_{2} \mathrm{O} \mathrm{NCBs} / \mathrm{CS}$ NPs composites material are as followed: $\mathrm{Cu}(23.99 \%), \mathrm{O}(38.18 \%), \mathrm{C}(33.61 \%)$ and other elements. Furthermore, the $\mathrm{Cu}_{2} \mathrm{O} \mathrm{NCBs} / \mathrm{CS}$ NPs composite is confirmed as a potential and promising photocatalyst material for $p$-nitrophenol reduction with a treatment efficiency of $>55 \%$ at a treatment time of $25 \mathrm{~min}$. Thus, this study has proposed a cheap nanocomposites catalyst instead of an expensive noble material system in the treatment of $p$-nitrophenol for the environmental problems.

\section{REFERENCES}

1. Zelekew O.A., Kuo D. (2016) A two-oxide nanodiode system made of double-layered p-type $\mathrm{Ag}_{2} \mathrm{O} @$ n-type $\mathrm{TiO}_{2}$ for rapid reduction of 4-nitrophenol. Physical Chemistry Chemical Physics, 18(6), 4405-4414. https://doi.org/10.1039/C5CP07320K

2. Kulkarni M., Chaudhari A. (2007) Microbial remediation of nitro-aromatic compounds: an overview. Journal of Environmental Management, 85(2), 496-512. https://doi.org/10.1016/j.jenvman.2007.06.009

3. Tchieno F.M.M., Tonle I.K. (2018) p-Nitrophenol determination and remediation: An overview. Reviews in Analytical Chemistry, 37(2). https://doi.org/10.1515/revac-2017-0019

4. DinM.I.,KhalidR., HussainZ., HussainT., MujahidA., et al. (2020) Nanocatalytic assemblies for catalytic reduction of nitrophenols: A critical review. Critical Reviews in Analytical Chemistry, 50(4), 322-338. https://doi.org/10.1080/10408347.2019.1637241

5. Environmental protection agency U.S. (2014) Priority Pollutant List https://www.epa.gov/sites/ default/files/2015-09/documents/priority-pollutantlist-epa.pdf (Accessed June 2021).

6. Liu J., Li J., Meng R., Jian P., Wang L. (2019) Silver nanoparticles-decorated- $\mathrm{Co}_{3} \mathrm{O}_{4}$ porous sheets as efficient catalysts for the liquid-phase hydrogenation reduction of $p$-Nitrophenol. Journal of Colloid Interface Science, 551, 261-269. https://doi.org/10.1016/j.jcis.2019.05.018

7. Guo Y., Dai M., Zhu Z., Chen Y., He H., et al. (2019) Chitosan modified $\mathrm{Cu}_{2} \mathrm{O}$ nanoparticles with high catalytic activity for $p$-nitrophenol reduction. Applied Surface Science, 480, 601-610. https://doi.org/10.1016/j.apsusc.2019.02.246
8. Gu Y., Zhang Y., Zhang F., Wei J., Wang C., et al. (2010) Investigation of photoelectrocatalytic activity of $\mathrm{Cu}_{2} \mathrm{O}$ nanoparticles for $p$-nitrophenol using rotating ring-disk electrode and application for electrocatalytic determination. Electrochimica Acta, 56(2), 953-958. https://doi.org/10.1016/j.electacta.2010.09.051

9. Zhang S., Shang W., Yang X., Zhang S., et al. (2013) Immobilization of lipase using alginate hydrogel beads and enzymatic evaluation in hydrolysis of $p$-nitrophenol butyrate. Bulletin of the Korean Chemical Society, 34(9), 2741-2746. https://doi.org/10.5012/bkcs.2013.34.9.2741

10. Liu J., Yan X., Wang L., Kong L., Jian P. (2017) Three-dimensional nitrogen-doped graphene foam as metal-free catalyst for the hydrogenation reduction of $p$-nitrophenol. Journal of Colloid Interface Science, 497, 102-107. https://doi.org/10.1016/j.jcis.2017.02.065

11. Lu H., Yin H., Liu Y., Jiang T., Yu L. (2008) Influence of support on catalytic activity of $\mathrm{Ni}$ catalysts in p-nitrophenol hydrogenation to $p$-aminophenol. Catalysis Communications, 10(3), 313-316. https://doi.org/10.1016/j.catcom.2008.09.015

12. Visibile A., Wang R.B., Vertova A., Rondinini S., Minguzzi A., et al. (2019) Influence of strain on the band gap of $\mathrm{Cu}_{2} \mathrm{O}$. Chemistry of Materials, 31(13), 4787-4792. https://doi.org/10.1021/acs.chemmater.9b01122

13. Zheng Z., Huang B., Wang Z., Guo M., Qin X., et al. (2009) Crystal faces of $\mathrm{Cu}_{2} \mathrm{O}$ and their stabilities in photocatalytic reactions. The Journal of Physical Chemistry C, 113(32), 14448-14453. https://doi.org/10.1021/jp904198d

14. Wang Z., Wang H., Wang L., Pan L. (2009) Controlled synthesis of $\mathrm{Cu}_{2} \mathrm{O}$ cubic and octahedral nano-and microcrystals. Crystal Research Technology: Journal of Experimental Industrial Crystallography, 44(6), 624-628. https://doi.org/10.1002/crat.200900136

15. Ahmed A., Gajbhiye N.S., Joshi A.G. (2011) Low cost, surfactant-less, one pot synthesis of $\mathrm{Cu}_{2} \mathrm{O}$ nano-octahedra at room temperature. Journal of Solid State Chemistry, 184, 2209-2214. https://doi.org/10.1016/j.jssc. 2011.05.058

16. Wang Y., Huang D., Zhu X., Ma Y., Geng H., et al. (2014) Surfactant-free synthesis of $\mathrm{Cu}_{2} \mathrm{O}$ hollow spheres and their wavelength-dependent visible photocatalyticactivitiesusing LEDlampsascoldlight sources. Nanoscale Research Letters, 9(1), 1-8. https://doi:10.1186/1556-276X-9-624

17. Yu Y., Du F.P., Jimmy C.Y., Zhuang Y., Wong P.K. (2004) One-dimensional shape-controlled preparation of porous $\mathrm{Cu}_{2} \mathrm{O}$ nano-whiskers by using $\mathrm{CTAB}$ as a template. Journal of Solid State Chemistry, 177(12), 4640-4647. https://doi.org/10.1016/j.jssc.2004.10.025 
18. Naz G., Shamsuddin M., Butt F.K., Bajwa S.Z., Khan W.S., et al. (2019) $\mathrm{Au} / \mathrm{Cu}_{2} \mathrm{O}$ core/shell nanostructures with efficient photoresponses. Chinese Journal of Physics, 59, 307-316. https://doi.org/10.1016/j.cjph.2019.03.008

19. Xu C., Cao L., Su G., Liu W., Liu H., et al. (2010) Preparation of $\mathrm{ZnO} / \mathrm{Cu}_{2} \mathrm{O}$ compound photocatalyst and application in treating organic dyes. Journal of Hazardous Materials, 176(1-3), 807-813. https://doi.org/10.1016/j.jhazmat.2009.11.106

20. Cheung R.C.F., Ng T.B., Wong J.H., Chan W.Y. (2015) Chitosan: an update on potential biomedical and pharmaceutical applications. Marine Drugs, 13(8), 5156-5186. https://doi.org/10.3390/md13085156

21. Kumari S., Kishor R. (2020) Handbook of Chitin Chitosan: Volume 1: Preparation Properties, 1st Ed., Elsevier, 1-33. https://doi.org/10.1016/ C2018-0-03014-5

22. Divya K., Jisha M., (2018) Chitosan nanoparticles preparation and applications. Environmental Chemistry Letters, 16(1), 101-112. https://doi.org/10.1007/s10311-017-0670-y

23. Chen J.Y., Zhou P.J., Li J.L., Wang Y. (2008) Studies on the photocatalytic performance of cuprous oxide/chitosan nanocomposites activated by visible light. Carbohydrate Polymers, 72, 128-132. https://doi.org/10.1016/j.carbpol.2007.07.036

24. Cao C., Xiao L. (2014) Preparation and visible-light photocatalytic activity of $\mathrm{Cu}_{2} \mathrm{O} /$ PVA/Chitosan composite films. Advanced Materials Research, 1015, 623-626. https://doi.org/10.4028/www.scientific.net/ AMR.1015.623
25. Cao C., Xiao L., Liu L., Zhu H., Chen C., et al. (2013) Visible-light photocatalytic decolorization of reactive brilliant red $\mathrm{X}-3 \mathrm{~B}$ on $\mathrm{Cu}_{2} \mathrm{O}$ /crosslinkedchitosan nanocomposites prepared via one step process. Applied Surface Science, 271, 105-112. https://doi.org/10.1016/j.apsusc.2013.01.135

26. Ali M.E.A., Aboelfadl M.M.S., Selim A.M., Khalil H.F., Elkady G.M. (2018) Chitosan nanoparticles extracted from shrimp shells, application for removal of $\mathrm{Fe}(\mathrm{II})$ and $\mathrm{Mn}(\mathrm{II})$ from aqueous phases. Separation Science Technology, 53(18), 2870-2881. https://doi.org/10.1080/01496395.2018.1489845

27. Sivakami M., Gomathi T., Venkatesan J., Jeong H., et al. (2013) Preparation and characterization of nano chitosan for treatment wastewaters. International Journal of Biological Macromolecules, 57, 204-212. https://doi.org/10.1016/j.ijbiomac.2013.03.005

28. Sasmal A.K., Dutta S., Pal T. (2016)A ternary $\mathrm{Cu}_{2} \mathrm{O}-$ Cu-CuO nanocomposite: A catalyst with intriguing activity. Dalton Transactions, 45(7), 3139-3150. https://doi.org/10.1039/C5DT03859F

29. Mandlimath T.R., Gopal B. (2011) Catalytic activity of first row transition metal oxides in the conversion of $p$-nitrophenol to $p$-aminophenol. Journal of Molecular Catalysis A: Chemical, 350(1-2), 9-15. https://doi.org/10.1016/j.molcata.2011.08.009

30. Zhang J., Yan Z., Fu L., Zhang Y., Yang H., et al. (2018) Silver nanoparticles assembled on modified sepiolite nanofibers for enhanced catalytic reduction of 4-nitrophenol. Applied Clay Science, 166, 166-173. https://doi.org/10.1016/j.clay.2018.09.026 